\title{
MEMBANGKITKAN POTENSI DIRI DAN MINAT SISWA DALAM BELAJAR BAHASA ARAB DENGAN NILAI-NILAI HYPNOTEACHING
}

\author{
Akhsan Akhsan, Ahmadi Muhammadiyah \\ ahsanthayyib@gmail.com \\ Univesitas Ibrahimy Situbondo
}

\begin{abstract}
:
The most important obstacle today in learning Arabic is that the awareness of the importance of Arabic in students has not been fully formed. This fact occurs because Arabic learners and teachers, especially in Indonesia, are still trapped in policies (regulations regarding the continuity of learning in class, time and space issues), curriculum (objectives and boundaries of competence), and methodology (theories that must be put into practice). Coupled with the "image" and "mindset" that has been formed in society that Arabic is only the language of religion. Make students aware that Arabic is one of the international languages and it is useful in their world life. This problem is a fundamental problem which academics and Arabic language practitioners have to slowly resolve. The purpose of learning Arabic must be shifted from "teaching the language" to "teaching the language", teaching methodology must be "constructed" from practicing theory and curriculum to exploring potential and arousing student interest. With the application of Hipnoteaching values, it is hoped that teachers will be able to design Arabic language learning that is able to increase the potential, talents, and interests of students in Arabic. Hypnoteaching values according to the results of this study, it can be adopted in Arabic learning with the following concepts : 1) Place, Location and Arabic Study Room Setting, 2) Mental and psychological settings of Arabic teachers and students, 3) Early Learning Stimulus, 4) Setting communication styles in Arabic learning, 5) Enabling the class with practice is not just a transfer of knowledge or knowledge of Arabic, 6) Evaluation and 7) Closing Activities of Learning Arabic.
\end{abstract}

Keywords: Self Potential, Student Interests, Learning Arabic, Hypnoteaching Values

\section{PENDAHULUAN}

Pengembangan kurikulum pendidikan di Indonesia sampai saat ini belum memberikan hasil sesuai dengan yang diharapkan. ${ }^{1}$ Salah satunya karena faktor guru. karena gurulah yang menjadi aktor terdepan dalam implementasi kurikulum, disamping beberapa faktor lainnya. Sebaik apapun sebuah kurikulum, selama gurunya

\footnotetext{
${ }^{1}$ Terhitung sejak tahun 1968, kurikulum di Indonesia sudah mengalami perubahan dan pengembangan sebanyak 7 kali perubahan, yakni tahun 1968 untuk memperbaiki kurikulum sebelumnya,kurikulum 1975,kurikulum 1984, kurikulum 1994, kurikulum 2004 yang dikenal dengan Kurikulum Berbasis Kompetensi (KBK), Kurikulum tahun 2006 yang dikenal dengan Kurikulum Tingkat Satuan Pendidikan (KTSP), dan kurikulum 2013 yang berlaku sampai sekarang.
}

pasif dan stagnan, maka kualitas lembaga pendidikan akan merosot tajam, demikian pula sebaliknya. ${ }^{2}$ Oleh sebab itu, guru sebagai aktor yang terlibat langsung dalam proses pembelajaraan seharusnya mampu berinovasi ${ }^{3}$ dan berkreasi.

Dalam proses belajar mengajar, sebuah metode akan mengalami kegagalan

\footnotetext{
${ }^{2}$ Jamal Ma'mur Asmani, Tips Menjadi Guru Inspiratif, Kratif, dan Inovatif, (Yogyakarta: Diva Press, 2010), hlm. 6

${ }^{3}$ Rogers memberikan batasan bahwa yang dimaksud dengan inovasi adalah "suatu gagasan, praktik, atau obyek benda yang dipandang baru oleh seseorang atau kelompok calon penerima lainnya". Kata "baru" tersebut bersifat sangat relatif, bisa karena seseorang baru mengetahui, atau bisa juga karena baru mau menerima meskipun sudah lama tahu, lihat Rogers, E. M., Diffusion of Innovations. (London: The Free Press, 1983) hal. 11
} 
manakala metode tersebut menjadi tempat bersandar terlalu lama, dan tidak sesuai dengan kondisi dan situasi dimana dan kapan proses belajar mengajar berlangsung, tidak terkecuali dalam pembelajaran Bahasa Arab. Salah satu yang bisa membantu dalam proses belajar mengajar, adalahdengan cara berkomunikasi dengan alam bawah sadar siswa. ${ }^{4}$ Salah satu metode komunikasi yang digunakan dan cukup populer saat ini adalah teknik hipnosis. Hipnotis merupakan gaya komunikasi untuk mempengaruhi seseorang dengan mengubah tingkat kesadarannya. ${ }^{5}$ Dalam dalam proses pembelajaran hipnotis dikenal dengan istilah hypno teaching. Hipnotis tidak hanya berguna untuk mengatasi permasalahan yang menyangkut kondisi fisik maupun psikis, melainkan juga dapat digunakan dalam upaya mengoptimalkan proses pembelajaran.

Membangkitkan potensi dan bakat siswa dalam belajar, dalam hal ini belajar bahasa Arab, merupakan tugas guru bahasa Arab. Untuk membangkitkan potensi dan bakat siswa bahasa Arab, maka seorang guru bahasa Arab harus mengetahui psikologis dan latar belakang siswanya terlebih dahulu. Guru harus mendeteksi potensi dan bakat siswa melalui pendekatan personal dan model pembelajaran yang menyenangkan serta menenangkan. Lalu apa nilai-nilai yang dapat diadopsi untuk melakukan hal itu semuanya, tentunya menggunakan pendekatan hipnoteaching. Artikel ini menggambarkan tentang teori dasar hipnoteaching dan hal-hal yang perlu dilakukan oleh guru bahasa Arab dalam membangkitkan potensi dan bakat siswa dalam belajar bahasa Arab.

\section{Metode Penelitian}

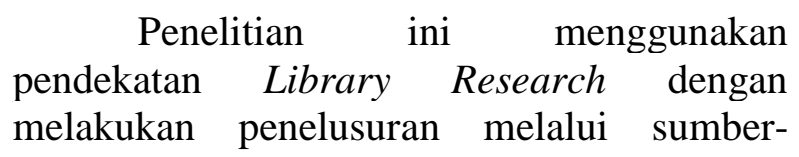

${ }^{4}$ Agung Webe, Smart Teaching 5 Metode Efektif Lejitkan Prestasi Anak didik, (Yogyakarta: Jogja Bangkit Publisher, 2010), hlm. 36

${ }^{5}$ Ade W. Gunawan, Hypnosis: The Art of Subconscious Communication, Meraih Sukses dengan Kekuatan Pikiran, (Jakarta: Pt. Gramedia Utama, 2007), hlm. 3 sumber terkait. Melalui sumber terkait peneliti melakukan analisis dan menyimpulkan tentang gambaran teori dan cara bagaimana membangkitkan potensi dan bakat siswa dalam belajar bahasa Arab.

\section{Dasar Pendekatan Hipno Teaching}

Hipno teaching berembrio dari aliran hipnotis. John Af mengemukakan bahwa usia ilmu hipnotis sama dengan usia ilmu sihir, mistik, falak, perwatakan (tabiat), dan ilmu ketabiban. Hal tersebut sebagaimana ditemukan dalam kitab-kitab kuno warisan Yunani, Mesir, India dan $\mathrm{Arab}^{6}$.Ilmu hipnotis mulai dipopulerkan oleh Franz Anton Mesmer, seorang tabib di kota Wina pada abad ke 18. Dia memakai ilmu hipnotis untuk mengobati pasiennya yang sakit saraf. Tekniknya di dasarkan pada sifat alamiah magnetisme hewani. Masmer beranggapan bahwa pasiennya sembuh karena mendapat transfer magnetisme hewani dari dirinya. ${ }^{7}$ Kemudian teknik mesmer di ekperimenkan oleh seorang dokter dari Inggris pada abad ke- 19 bernama James Braid, yang menyimpulkan bahwa hipnotis bersifat psikologis.

Kemudian, sesuai rekomendasi dari American Medical Associationpada tahun 1958, hipnosis bisa digunakan dalam dunia kedokteran. Dan kemudian menjadi salah satu ilmu yang resmi dipelajari dan diakui dalam dunia kedokteran setelah terbentuknyaThe British Medical Association dan Italian Medical Association for the Study of Hypnosis. ${ }^{8}$

Ada lima karakteristik yang harus diketahui jika seseorang dalam keadaan terhipnotis. Kelima kondisi tersebut adalah : ${ }^{9}$

\footnotetext{
${ }^{6}$ John Af, Hipnotis Modern, (Djap Djempoel, 2009), hlm. 30

${ }^{7}$ Adi $\quad$ W. Gunawan, Hypnosis: The Art of Subconscious Communication, Meraih Sukses dengan Kekuatan Pikiran, (Jakarta: Pt. Gramedia Utama, 2007), hlm. 6

${ }^{8}$ Setia I. Rusli \& Johanes Arifin Wijaya, The secret Of Hypnosis: Mengungkap Rahasia hipnosis, mencegah, menghindari, dan menghadapi kejahatan Hipnosis, (Jakarta: Penebar Plus ${ }^{+}$2009), hlm. 36

${ }^{9}$ Ade W. Gunawan, Hypnosis: The Art of Subconscious Communication, Meraih Sukses dengan
} 
Pertama, Relaksasi fisik yang dalam. Hal tersebut untuk membawa subjek pindah dari alam pikiran sadar ke alam pikiran bawah sadar dengan melibatkan konsentrasi fisik. Pada Saat tubuh dalam kondisi rileks, pikiran akan menjadi rileks. Dan pada saat dalam kondisi rileks, gelombang otak akan turun dari beta, alpha, theta dan delta. Kedua, Perhatian yang sangat terpusat. Pada saat kondisi normal, pikiran sadar dipenuhi oleh stimulus melalui panca indera, berbeda dengan dengan pada saat kondisi hipnotis yang membuat perhatian terfokus pada satu stimulus saja.

Ketiga, Kemampuan indra mengalami peningkatan. Hal tersebut sesuai dengan hasil eksperimen dengan menggunakan hipnosis yang menunjukan bahwa kemampuan indra pada saat ter-hipnotis meningkat. Indra beroperasi lebih akurat apabila fungsinya diarahkan dengan menggunakan sugesti. Keempat, Pengendalian refleks dan aktivitas fisik. Pada waktu dihipnotis, detak jantung seseorang dapat dikendalikan, bagian tubuhnya bisa dibuat mati rasa, sirkulasi darahnya dapat ditingkatkan atau diturunkan.

Kelima, adanya respon terhadap pengaruh pasca hipnotis. Sugesti yang diberikan pada saat hypnosis -dengan catatan kondisi sugesti tersebut tidak bertentangan dengan nilai dasar yang dipegang oleh subjek-, akan tetap dijalankan oleh subjek setelah ia tersadar kembali. Sugesti positif, baik, dan menguntungkan subjek, akan lebih mudah diterima daripada sugesti negative, jelek dan tidak menguntungkan subjek.

Hipnotis dibutuhkan untuk menonaktifkan critical area ${ }^{10}$ pada diri seseorang, sehingga informasi yang diperoleh seseorang dapat diserap secara mudah dan

Kekuatan Pikiran, (Jakarta: Pt. Gramedia Utama, 2007), hlm. 16-17

${ }^{10}$ Informasi yang masuk melalui panca indera tidak secara langsung diserap oleh pikiran bawah sadar seseorang, namun membutuhkan daya analisis dari pikiran sadar yang disebut critical area. Critical area ini diperlukan dalam kehidupan sehari-hari sebagai filter informasi untuk menyeleksi hal-hal yang membahayakan dan bertentangan dengan diri. tersimpan di pikiran alam bawah sadarnya. ${ }^{11}$ Hypnoteaching yang merupakan bagian dari ilmu hipnotis, merupakan seni berkomunikasi dengan cara memberikan sugesti agar seseorang dalam hal ini siswa adalah siswa menjadi lebih cerdas, imajinatif dan kreatif. ${ }^{12}$

Implementasi metode Hypnoteaching dalam proses belajar mengajar adalah dengan mengkomunikasikan pikiran bawah sadar yang bisa menimbulkan sugensti kepada para siswa untuk berkonsentrasi terhadap materi yang diajarkan. Pikiran bawah sadar akan lebih mendominasi yakni $88 \%$ dari pikiran sadarnya yang hanya berkisar $12 \% .{ }^{13}$

Pikiran bawah sadar lebih bersifat netral dan sugestif. Pikiran bawah sadar inilah yang merupakan sebuah memori jangka panjang manusia dengan menyimpan berbagai peristiwa, baik yang berdasarkan pengalaman pribadi (eksperimental) maupun orang lain (induksi). ${ }^{14}$

Sementara itu kondisi hipnotis dibagi menjadi dua yaitu : hipnotis ringan (light hypnosis) dan hipnotis dalam (deep hypnosis). Dalam proses belajar mengajar lebih menggunakan teknik light hypnosis, yang dalam kondisi tersebut gelombang pikir seseorang berada pada light alpha.

$\begin{array}{cccc}\text { Sedangkan } & \begin{array}{c}\text { langkah-langkah } \\ \text { dilakukan }\end{array} & \text { dasar } \\ \text { dalam }\end{array}$
mengimplementasikan metode hypnoteaching menurut Ibnu Hajar adalah $:^{15}$

1. Membangkitkan Niat dan motivasi

Hal pertama yang perlu diperhatikan oleh guru yang akan menggunakan metode hypnoteaching adalah harus bisa menanamkan niat yang kuat pada diri siswa. Niat tersebut akan memunculkan

\footnotetext{
${ }^{11}$ Andri Hakim, "Hypnosis in The Teaching: Cara Dahsyat Mendidik dan Mengajar”, (Jakarta: Visimedia, 2011), hlm. 46-47

${ }^{12}$ Ibnu Hajar, Hypno Teaching:

Memaksimalkan Hasil Proses Belajar-Mengajar dengan Hipnoterapi, (Yogyakarta: Diva Press, 2011), hlm. 75

${ }^{13}$ Willy Wong \& Andri Hakim, "Dahsyatnya
Hipnosis", (Jakarta: Visimedia, 2010), hlm. 18
${ }^{14}$ Andri Hakim, "Hypnosis in The Teaching: Cara Dahsyat Mendidik dan Mengajar”, (Jakarta: Visimedia, 2011), hlm. 27

${ }^{15}$ Ibnu Hajar, Op. Cit, h. 100-104
} 
motivasi yang tinggi dan komitmen yang kuat pada diri siswa dalam belajar.

2. Pacing

Pacing merupakan penyamaan posisi, bahasa, gerak tubuh, serta gelombang otak dengan orang lain dalam hal ini adalah siswa, dengan : a) membayangkan usia guru setara dengan siswa; $b$ ) menggunakan bahasa yang sering digunakan oleh siswa; c) melakukan gerakan-gerakan dan mimik wajah sesuai dengan tema atau pokok bahasan; d) mengaitkan tema atau pokok bahasan dengan tema yang menjadi Trend di kalangan para siswa; e) selalu up date pengetahuan yang berkaitan dengan tema atau pokok bahasan

3. Leading

Leading berarti memimpin atau mengarahkan. Setelah pacing, proses selanjutnya dalam hypnoteaching adalah leading. Dalam praktik pembelajaran, guru harus bisa mengkombinasikan antara peacing dan leading, dimana kedua teknik tersebut dapat menciptakan suasana pembelajaran yang kondusif dan efektif.

4. Kata positif

Langkah pendukung selanjutnya adalah metode hypnoteaching adalah penggunaan bahasa atau kata-kata yang positif. Kata-kata positif sangat sesuai dengan sistem kerja pikiran alam bawah sadar yang tidak menerima sugesti negatif.

5. Berikan pujian

Pujian merupakan salah satu cara untuk membentuk konsep diri seseorang Pujian merupakan reward yang penting untuk peningkatan harga diri seseorang. Guru perlu memberikan pujian pada siswa khususnya ketika ia berhasil melakukan sesuatu atau mencapai prestasi tertentu, sekecil apapun bentuk prestasinya, termasuk ketika ia berhasil melakukan perubahan positif pada dirinya sendiri. Dengan pujian, seseorang akan terdorong untuk melakukan yang lebih dari sebelumnya.

6. Modeling

Yaitu memberi keteladanan melalui ucapan dan perilaku yang konsisten. Hal tersebut sangat penting dan menjadi salah satu kunci hypnoteaching. Setelah siswa menjadi nyaman dengan guru, mereka bisa diarahkan sesuai keinginan guru, dengan modal kalimat-kalimat positif. Perlu pula kepercayaan (trust) siswa pada guru dimantapkan dengan perilaku guru yang dilakukan secara konsisten melalui ucapan dan tindakan, sehingga guru akan selalu menjadi figure yang dipercaya.

Sebagaimana dijelasakan di atas, Hipnotis dalam pembelajaran diperlukan untuk membendung aktifitas critical area siswa. pada saat aktifitas critical area siswa berada pada level cukup signifikan, informasi akan lebih sulit diterima dan direkam dalam memori jangka panjang (alam bawah sadar). Dalam keadaan ini, siswa akan menolak informasi-informasi yang bertentangan dengan keinginannya. Sebagai contoh, ketika siswa tidak menyukai salah satu materi pelajaran tentu ia akan sulit menerima informasi yang disampaikan oleh guru. Hal tersebut terjadi karena aktifitas critical area siswa cukup tinggi. Oleh sebab itu, maka seorang guru harus mampu menembus critical area tersebut melalui metode hypnoteaching.

Andri Hakim mengungkapkan bahwa untuk dapat menembus CA, seorang guru harus memahami beberapa hal dalam proses hipnosis di antaranya: 1) Relaxation; proses pembelajaran harus dimulai dengan suasana yang menyenangkan yang dapat membuat siswa relaks, hal ini diperlukan untuk mengistirahatkan aktifitas CA. Relaxation ini bisa diciptakan dengan memperhatikan suasana kelas, penampilan pengajar dan kalimat pembuka yang dapat membangun motivasi siswa; 2) Mind Focus \& Alpha State; hipnosis dalam pembelajaran bekerja pada level gelombang alpha yaitu mengkondisikan siswa untuk memasuki kondisi hipnosis (hypnosis state). Dalam kondisi ini siswa diharapkan lebih mudah merekam informasi ke dalam memori jangka panjang; 3) Komunikasi bawah sadar; komunikasi terkadang kurang efektif dan efisien. Hal ini disebabkan tidak adanya komunikasi bawah sadar yang mendukung terjadinya sebuah "two way 
communication heart to heart" atau komunikasi dua arah dari hati ke hati". Dengan demikian maka diperlukan beberapa hal untuk membangun komunikasi bawah sadar di antaranya: a) informasikan hal yang akan disampaikan kepada siswa; b) guru harus memperhatikan cara penyampaian dan cara mengatakan informasi tersebut; c) kondisi atau situasi yang kondusif.

Dalam hal pembelajaran bahasa Arab, seorang guru bisa menjadikan metode hypnotaching sebagai metode alternatif untuk bisa menciptakan suasana pembelajaran yang efektif, kondusif dan menyenangkan dengan cara membawa siswa ke arah suasana yang rileks dengan mengubah gelombang pikiran siswa ke alam bawah sadar. Bagaimakah gambaran penerapan nilai-nilai hypnoteaching dalam pembelajaran bahasa Arab :

\begin{tabular}{|l|l|}
\hline & $\begin{array}{l}\text { Biah lughawiyah } \\
\text { yaitu dengan } \\
\text { mendesain } \\
\text { lingkungan belajar } \\
\text { yang } \\
\text { menyenangkan, jika } \\
\text { lokasinya di pondok } \\
\text { pesantren maka } \\
\text { sekeliling pondok } \\
\text { pesantren dan } \\
\text { disetiap sudut } \\
\text { pasanglah papan } \\
\text { yang berisi } \\
\text { Setting Tempat, } \\
\text { Lokasi, Ruang } \\
\text { Belajar bahasa } \\
\text { Arab }\end{array}$ \\
$\begin{array}{l}\text { ungkapan bahasa } \\
\text { Arab (uslubiah), dan } \\
\text { kata-kata mutiara), } \\
\text { begitu juga di } \\
\text { ruangan sekolah. }\end{array}$ \\
\hline $\begin{array}{l}\text { Setting mental dan } \\
\text { psikologi diri guru } \\
\text { dan siswa bahasa } \\
\text { Arab }\end{array}$ & $\begin{array}{l}\text { Guru bahasa Arab } \\
\text { tegas namun tidak } \\
\text { menakutkan, } \\
\text { menyenangkan } \\
\text { dipandang tidak } \\
\text { membuat siswa } \\
\text { bosan dengan } \\
\text { berpakaian rapi } \\
\text { (good looking), guru }\end{array}$ \\
\hline
\end{tabular}

\begin{tabular}{|l|l|}
\hline adalah role mode \\
(berbahasa arablah \\
sehari-hari dikelas), \\
guru adalah ibarat \\
kamus berjalan \\
ketika siswa ingin \\
mengetahui segala \\
sesuatu tentang \\
bahasa Arab, maka \\
guru harus serba \\
mengetahui dan \\
menguasai keilmuan \\
bahasa Arab, guru \\
bahasa arab harus \\
mengayomi, \\
momong siswa, dan \\
mampu berposisi \\
sebagai seorang \\
ayah dan teman \\
tidak hanya seorang \\
guru artinya guru \\
harus mengikuti \\
perkembangan \\
pergaulan siswa \\
namun tetap \\
menjaga marwah \\
keguruannya (guru \\
update tentang hal- \\
hal milenial), \\
kondisikan siswa \\
tenang dan tanpa \\
problem sebelum \\
belajar.
\end{tabular}




\begin{tabular}{|c|c|}
\hline & $\begin{array}{l}\text { kehidupan. Guru } \\
\text { sesekali } \\
\text { menggunakan LCD } \\
\text { untuk melihat film- } \\
\text { film berbahasa Arab } \\
\text { yang edukatif dan } \\
\text { membangkitkan } \\
\text { semangat belajar } \\
\text { bahasa Arab, cerita } \\
\text { inspiratif } \\
\text { pengalaman belajar } \\
\text { guru (perjalanan } \\
\text { karier guru dibidang } \\
\text { bahasa Arab), } \\
\text { mengkondisikan } \\
\text { psikologis dan } \\
\text { pemusatan pikiran } \\
\text { siswa dengan } \\
\text { relaksasi sebelum } \\
\text { belajar (bercanda } \\
\text { dan cerita) }\end{array}$ \\
\hline $\begin{array}{l}\text { Setting gaya } \\
\text { berkomunikasi } \\
\text { dalam } \\
\text { pembelajaran } \\
\text { bahasa Arab }\end{array}$ & $\begin{array}{l}\text { Tidak menyuruh, } \\
\text { tidak memaksa, } \\
\text { tidak otoriter namun } \\
\text { lebih sebagai } \\
\text { fasilitator, teman } \\
\text { belajar, solutif } \\
\text { bukan problematik, } \\
\text { menyenangkan, dan } \\
\text { edukatif } \\
\text { (memberikan contoh } \\
\text { dan teladan), guru } \\
\text { harus kreatif dan } \\
\text { aktif. (peacing dan } \\
\text { modeling) }\end{array}$ \\
\hline $\begin{array}{l}\text { Menghidupkan } \\
\text { kelas dengan } \\
\text { praktek tidak } \\
\text { sekedar transfer } \\
\text { ilmu atau } \\
\text { pengetahuan } \\
\text { bahasa Arab }\end{array}$ & $\begin{array}{l}\text { Praktek berbicara, } \\
\text { praktek menulis, } \\
\text { praktek membaca, } \\
\text { praktek mendengar, } \\
\text { diskusi dan analisis, } \\
\text { problem solving. } \\
\text { Media yang } \\
\text { menyenangkan, } \\
\text { media tegnologi dan } \\
\text { sebagainya. }\end{array}$ \\
\hline $\begin{array}{l}\text { Evaluasi } \\
\text { pembelajaran } \\
\text { bahasa Arab }\end{array}$ & $\begin{array}{l}\text { Mengadakan } \\
\text { evaluasi kelas, } \\
\text { berdiskusi }\end{array}$ \\
\hline
\end{tabular}

\begin{tabular}{|c|c|}
\hline & $\begin{array}{l}\text { pengalaman belajar } \\
\text { di kelas, berbagai } \\
\text { problem dan solusi, } \\
\text { dan tindak lanjut }\end{array}$ \\
\hline $\begin{array}{l}\text { Kegiatan penutup } \\
\text { pembelajaran } \\
\text { bahasa Arab }\end{array}$ & $\begin{array}{l}\text { Memberikan tugas } \\
\text { tentang pengalaman } \\
\text { yang dihadapai saat } \\
\text { belajar di rumah, } \\
\text { memberikan tugas } \\
\text { tentang apa yang } \\
\text { dialami dalam } \\
\text { kehidupan siswa } \\
\text { berhubungan } \\
\text { dengan bahasa } \\
\text { Arab, memberikan } \\
\text { kesan untuk minat } \\
\text { siswa bertemu } \\
\text { kembali dikelas, } \\
\text { memberikan } \\
\text { apresasi yang } \\
\text { membangkitkan } \\
\text { semangat belajar, } \\
\text { semangat minat, dan } \\
\text { mengembangkan } \\
\text { bakat. }\end{array}$ \\
\hline
\end{tabular}

\section{Potensi Diri Dan Minat Siswa Dalam Belajar}

Potensi dalam diri manusia di kategorikan dalam empat instrumen yaitu algharizah (insting), al-hawas (indra), al-'aql (kognisi), al-jasad (serta fisik). Potensi tersebut dapat dikembangkan dan membuat manusia berbeda satu dengan yang lainnya. ${ }^{16}$ Insting merupakan fitrah manusia yang telah digariskan oleh-Nya yang potensi yang langsung bisa diaplikasikan dalam kehidupan.

Indra selanjutnya adalah otak yang merupakan potensi utama manusia dalam mengatur segala hal yang akan dikerjakan manusia. Akal erat hubungannya dengan kecerdasan (intelegence). Banyak peneliti dari barat yang berbicara tentang intelegence, salah satunya adalah Howard Gagner. Dia

\footnotetext{
${ }^{16}$ Darwis Hude, Emosi: Penjelajahan ReligioPsikologis Tentang Emosi Manusia Di Dalam AlQuran, Jakarta: Erlangga, 2006, hlm. 95
} 
berpendapat bahwa manusia tidak ada yang bodoh, artinya setiap manusia memiliki kecerdasannya masing-masing, namun yang jadi problem adalah apakah manusia mampu menggali potensinya itu menjadi energi yang besar dalam hidupnya yang mampu merubah "pola pikir" dan "wordview" nya. Hal inilah yang dimaksud oleh penulis bahwa potensi yang dimaksud dalam artikel ini adalah tentang akal atau kecerdasan. Bagaimana siswa mampu mengembangkan potensi kecerdasannya dalam belajar bahasa Arab.Setidaknya, hal ini merupakan stimulus buat guru agar menyadari bagaimana cara mengembangkan potensi diri siswa dalam mempelajari bahasa Arab.

Minat merupakan suatu keadaan dimana seseorang mempunyai perhatian terhadap sesuatu dan disertai keinginan untuk mengetahui dan mempelajari ataupun membuktikan. ${ }^{17}$ Menurut W. S Winkel minat merupakan kecenderungan yang menetap untuk merasa tertarik terhadap bidang-bidang tertentu dan merasa senang turut serta dalam bidang itu. ${ }^{18}$ minat adalah kesadaran seseorang terhadap suatu objek, seseorang, suatu soal atau situasi tertentu yang mengadung sangkut paut dengan dirinya atau dipandang sebagai sesuatu yang sadar. ${ }^{19}$ minat adalah suatu rasa lebih suka dan rasa ketertarikan pada suatu hal atau aktivitas tanpa ada yang menyuruh. ${ }^{20}$

Menurut Crow ciri-ciri minat bisa di jelaskan berikut: 1) perhatian terhadap obyek yang diminati secara sadar dan spontan, wajar tanpa paksaan, 2) perasaan senang terhadap obyek yang menarik perhatian, 3) konsistensi terhadap obyek yang diminati selama onyek tersebut efektif bagi dirinya, 4) pencarian obyek yang diminati, 5) pengalaman yang didapat selama perkembangan individu dan bersifat bawaan.

17 Bimo, Pengantar Psikologi Umum, Yogyakarta: Andi Offside, 2016, hlm. 38

18 W.S Winkel, Peikologi Pendidikan dan Evaluasi Belajar, Gramedia, Jakarta, 1983, hlm.38

19 Witherington, Psikologi Pendidikan, Jakarta:Aksara Baru, 1985, hlm.38

${ }^{20}$ Sumadi Suryabrata, Psikologi Pendidikan, Grafindo Perkasa: Jakarta, 2002, hlm.68
Mengenali potensi diri seseorang bisa diketahui melalui kepribadian. Kepribadian diklasifikasikan menjadi dua macam yaitu : 1) kepribadian menarik (lot of personality), yang menggambarkan sifat mudah menarik simpati orang, mengesankan, berbudi pekerti, sopan santun, memberikan kesan menarik pada pertama kali, dan 2) kepribadian yang membosankan atau disebut no personality. Menunjukkan sifat-sifat yang tidak disukai orang, membosankan, kurang bersemangat, tidak menarik, tidak mendalam, dan mudah dilupakan. $^{21}$

Menurut Ibrahim el-Fiky, dalam bukunya berjudul "Personal Power" bahwa potensi diri dimulai dari "kekuatan kesadaran". ${ }^{22}$ Harapan adalah kekuatan kasatmata di balik semua pencapaian. Harapan adalah jangkar jiwa, stimulus tindakan, dan insentif bagi pencapaian. Robert Schuller mengatakan dalam bukunya, "The Be Happy Attitude" yaitu: "harapan akan melahirkan keyakinan, keyakinan memungkinkan adanya cinta, dan dengan hadirnya cinta, keajaiban akan terjadi". ${ }^{23}$ Hasrat itu adalah seperti keinginan namun lebih dalam, "dimana ada kemauan, disitu ada jalan".

\section{Cara Membangkitkan Potensi Diri Dan Minat Siswa Dalam Belajar Bahasa Arab}

Siswa merupakan bagian dari komponen pembelajaran yang merupakan bagian terpenting sebab berkaitan dengan obyek pembelajaran. Dalam pembelajaran abad 21, model pembelajaran bergeser dari "teacher centered" menuju "student centered". Tujuan belajar dari mengetahui sesuatu menjadi mempertanyakan terjadinya sesuatu itu dan implikasinya. Belajar untuk mempertanyakan "apa" mengalamai perluasan makna pembelajaran menjadi "kenapa" dan "bagaimana". Pembelajaran menjadi lebih filosofis, historis, dan lebih

21 Nana Syaodih Sukmadinata, Landasan Psikologis Proses Pendidikan, (Bandung: PT Remaja Rosdakarya, 2003), hlm. 134

${ }^{22}$ Ibrahim El-Fikry, Personal Power (Membuktikan 7 Rahasia Kekuatan Pribadi), Terj. Aisyah, (Kanada: Sales Master Press, 2002), hlm. 21

${ }^{23}$ Ibid, hlm. 60 
bermanfaat kedepan untuk membentuk karakter dan kepribadian. Siswa yang seharusnya aktif dalam proses pembelajaran bukan guru, sebab kebiasaan aktif itulah yang nantinya akan menentukan keberhasilan siswa berperan dimasyarakat. Hal ini ada hubungannya dengan outcome pembelajaran. Namun pada prakteknya pendekatan "student centered" tidak serta merta berjalan seperti yang direncanakan dan dirumuskan rapi dalam silabus atau perencanaan pembelajaran. Ada problem yang selalu muncul dalam pelaksaaannya, entah problem itu dari siswa sendiri maupun gurunya. Pada faktanya, banyak siswa siswa dewasa ini yang masih malas dalam belajar bahasa Arab, problem ini terindikasi dan dipengarahi baik dari dalam (internal) siswa yang berhubungan dengan minat ataupun kemampuan kecerdasan. Ternyata, faktor ekternal juga mempengaruhi keberhasilan dan kesuksesan belajar siswa seperti guru yang pasif dan kurang mampu mengkondisikan kelas atau siswa. Guru cenderung tidak memberikan stimulus agar siswa lebih antusias dalam belajar dan bergairah dengan mata pelajaran, namun guru lebih cenderung membosankan, membebankan materi, menakutkan dengan banyak tugas dan soal-soal.

Dalam pembelajaran bahasa Arab proble, diatas telah terjadi semuanya. Ditambah lagi kesan bahwa bahasa arab adalah mata pelajaran yang sulit dan terkesan rumit. Apalagi belajar ketatabahasaan (nahwu dan sharf). Maka sebenarnya di era abad 21ini, para pakar memberikan arahan baru dan model pembelajaran baru yang lebih mampu membangkitkan gairah siswa untuk menyenangi belajar bahasa Arab dan menstimulus mereka untuk berkarya atau menciptakan produk dalam bahasa Arab meskipun hanya berupa tulisan sederhana berbahasa Arab. Arah pemnbelajarannya adalah pembelajaran bermakna (otentik) dan long live study \{belajar seumur hidup). Menurut aturannya, proses pembelajaran bahasa Arab dikelas adalah sebagai tanggungjawab guru, meskipun siswanya yang harus aktif bukan berarti siswa dibiarkan tanpa pengawasan, dan bimbingan. Maka dalam pembelajaran bahasa Arab, guru yang bagus adalah guru yang mampu menjadi fasilitator yang profesional. Guru mampu menjadi solusi ditengah-tengah problematika atau kesulitan belajar siswa.

Menurut Howard Gagner tidak ada siswa yang bodoh, yang ada hanyalah problem bahwa guru tidak mampu menjadi guru yang profesional yang mampu memahami siswanya. Manusia diberi kelebihan oleh Allah berupa Akal. Secara fitrah, tanpa diajari manusia tetap akan mampu beradaptasi dengan lingkungan untuk mengajari dirinya sendiri dan menjadikan dirinya paham dan pintar. Anak-anak disekolah tidak seharusnya dipaksa untuk belajar sesuai kemauan kurikulum dan gurunya. Secara filosofis, kurikulum hanyalah media yang tersistematika untuk menstimulus agar siswa mengetahui kemana arah pengetahuannya. Karena kurikulum adalah media seharusnya memudahkan untuk belajar bukan menyulitkan atau menjadikan belajar jadi rumit.

Dalam teori Humanisme, siswa harusnya dibimbing bukan dipaksa untuk belajar ini itu, biarlah siswa menemukan cara belajarnya sendiri, kalau perlu berfikir sendiri memecahkan problem dalam belajarnya. Kenapa demikian, karena manusia memilik akal untuk berfikir dan mengikuti alur akalnya. ${ }^{24}$ Chomsky mengatakan bahwa manusia memiliki semacama chip dalam otaknya yang disebut dengan LAD, dan itu membantunya untuk mengembangkan bahasanya sendiri. ${ }^{25}$ Dalam teori Kontruktifisme, belajar bahasa seharusnya bersifat komunikatif, artinya bahasa harus dipraktekkan sesuai kondisi berbahasa siswa masing-masing. ${ }^{26}$ Sehingga ketika mereka berbahasa mampu untuk membentuk pola ungkapan dan kebahasaan mereka sendiri dan

\footnotetext{
${ }^{24}$ Abdul Qodir, "Humanistik” Teori Belajar Humanistik Dalam Meningkatkan Prestasi Belajar Siswa, Vol. 04, No.02, 2017, hlm. 191

${ }^{25}$ Bagus Andrian Permata, Teori GeneratifTransformatif Noam Chomsky dan Relevansinya Dalam Pembelajaran Bahasa Arab, Jurnal: Empirisma, Vol. 24, No. 2, Juli 2015, hlm.179-187

26 Suparlan, Teori Kontruktivisme Dalam Pembelajaran, Jurnal Islamika: Keislaman dan Ilmu Pendidikan, Vol. 1, No. 2, Juli 2019, hlm. 79-78
} 
mampu membentuk "biah lughawiyah" atau lingkungan berbahasa Arab.

Untuk mendeteksi tipe kecerdasan siswa membutuhkan waktu yang relatif tidak sebentar, artinya dibutuhkan kejelian dan kekonsistenan guru dalam mendeteksi baik didalam kelas maupun diluar kelas. Guru harus memiliki hubungan personal yang baik dengan setiap siswa, jika memungkinkan memahami latar belakang seluruh siswa dikelas baik yang berhubungan dengan keluarga siswa maupun berhubungan dengan siswanya sendiri.

Guru juga harus menggunakan metodologi pembelajaran bahasa Arab yang bervariasi dikelas. Guru cenderung lebih luwes dan tidak kaku dalam mengajar, artinya guru harus mampu mengikuti alur kebutuhan siswa dalam belajar tanpa memaksakan gaya belajar atau metode belajarnya terhadap siswanya. Dalam metode "ekletik", guru harus mampu mengkolaborasi beberapa metode agar siswa senang dalam belajar dikelas dan mampu menyerap pengetahuan disaat belajar dikelas. ${ }^{27}$ Dalam sebuah artikel yang membahas "post metode", disitu dijelaskan bahwa pada saat tertentu teori-teori dalam pembelajaran bahasa Arab sudah tidak bisa lagi diterapkan karena guru menemukan metode sendiri dalam mengajarnya. ${ }^{28}$ Inilah arah dimana belajar itu dibentuk oleh komponen didalamnya yaitu guru dan siswanya sendiri bukan metodologi yang membentuknya. Inilah yang diharapkan sesungguhnya dengan apa yang dinamakan model belajar abad 21 yaitu belajar secara merdeka. $^{29}$

Memberikan motivasi kepada siswa agar lebih bersemangat belajar adalah salah satu tugas guru. Begitu pula dalam

27 Fitri Alrasi, Pendekatan Metode Ekletik Terhadap Pembelajaran Bahasa Arab di AKPER Aisyiyah Padang, Jurnal Kajian dan Pengembangan Umat, Vol. 1, No. 1, 2018, hlm. 93-102

28 Muhbib Abdul Wahab, Pembelajaran Bahasa Arab di Era Post Metode, Arabiyat: Jurnal Pendidikan Bahasa Arab dan Kebahasaaraban, Vol. 2, No. 1, 2015, hlm. 60-74

Saripudin, Pengembangan Model Pembelajaran Abad 21 Dengan Menggunakan Tegnologi Web 2.0, Jurnal Teknodik, Vo. 19, No. 1, April 2015, hlm. 1-11 pembelajaran bahasa Arab. Memberikan motivasi dalam pembelajaran bahasa Arab dapat dilakukan dengan menceritakan kisahkisah para pakar bahasa Arab yang sukses dibidang bahasa Arab. Cerita tentang ulamaulama terdahulu bagaimana belajar dan mengembangkan bahasa Arab. Memberikan sekilas tentang sejarah bagaimana terbentuknya bahasa Arab dan perkembangannya pada masa sebelum islam, masa nabi Muhammad SAW, dan pada masa kekhalifahan. Bagaimana para khalifah mengembangkan bahasa Arab. Bagaimana mempertahankan keeksistensian bahasa Arab dalam perpolitikan dan pemerintahan pada masa bani Umayah, bani Abbasyiyah, Turki Ustmani dan sebagainya. Di era masa kini memberikan motivasi bisa juga dilakukan dengan mengajarkan pepatah-pepatah bahasa Arab (mahfudhat). Memberikan gambaran tentang sekilas puisi berbahasa Arab dan sebagainya.

Guru berperan penting dalam keteladanan. Seorang guru bahasa Arab yang ideal seharusnya mampu berbahasa dengan baik dan benar (fasih). Guru harus ideal secara keimuan bahasa Arab artinya guru bisa menulis Arab dengan baik, mampu berbicara bahasa Arab dan konsisten menggunakannya di dalam kelas. Guru juga mampu atau setidaknya memahami kaidah kebahasaaraban (nahwu dan sharf). Guru ketika memberikan tugas, tentunya harus dijelaskan dan dan diberikan contoh dulu, sampai siswa benarbenar memahami perintah dalam tugasnya. Guru harus konsinten dalam menilai, obyektif dan bermakna. Dalam proses pembelajaran harus ada refleksi materi, untuk mengetahui seberapa tingkat pemahaman siswa. Guru memberikan apresiasi yang baik ketika siswa mampu menjawab pertanyaan-pertanyaan yang diberikan dengan bentuk pujian atau hadiah jika perlu. Jika dalam pembelajaran terjalin hubungan emosial yang erat antara siswa dan guru, tentunya akan mempengaruhi keberhasilan pembelajaran bahasa Arab.

Dalam evaluasi program pembelajaran bahasa Arab ada istilah "konteks". Konteks adalah bagaimana mengevaluasi lingkungan latar belakang siswa, analisis kebutuhan siswa dalam belajar serta kondisi sekolah. 
Mendekati siswa secara sosial dan personal bisa dilakukan dengan meninjau keadaan keluarganya, bagaimana lingkungan dirumah dan sekitarnya apakah mendukungh dia untuk belajar. Pendidikan utama adalah ada dikeluarga, jika keadaan keluarga mendukung belajar siswa, maka kemungkinan besar siswa lebih mudah untuk sukses dalam belajarnya. Setiap individu memiliki personalitas berbeda-beda. Guru yang profesional harus mampu mengetahui psikologis siswanya. Artinya guru harus memahami bagaimana karakternya, guru harus memahami perasaannya, guru menyelami kedalam jauh kejiwaan siswanya. Maka itulah kenapa didalam pembelajaran ada teori psikologi yang mempengaruhi pembelajaran. Bahkan dalam pembelajaran bahasa Arab, ada istilah psikolinguistik sebagai ilmu yang mempelajari gejala berbahasa, pemerolehan bahasa, dan perilaku berbahasa.

Untuk menjadikan siswa senang dan tertarik dalam belajar, guru perlu menggunakan media yang menarik. Media bisa disesuaikan dengan jenjang umur siswa. Untuk anak jenjang SD bisa menggunakan medie visual atau audio visual. Anak-anak jenjang SD lebih menyukai sesuatu yang mengandung visual dan audio, karena sejatinya anak seumuran SD lebih senang dengan visualisasi. Untuk anak jenjang SMP bisa menggunakan media internet dan tegnologi berupa powerpoint dengan bantuan LCD. Media yang lain bisa berupa alat peraga dan sebagainya. Untuk anak jenjang SMA bisa menggunakan media sosial dan jejaring sosial seperti media whatsupp, instagram, telegram, facebook dan sebagainya. Bisa juga media berbasis android dan file tutorial. Untuk jenjang perguruan tinggi bisa menggunakan media jejaring sosial seperti komunitas atau club bahasa Arab.

Pada era milenial ini, para siswa sudah melek tegnologi. Mereka sudah paham dan mengerti betul tentang perkembangan tegnologi. Perkembangan tegnologi itu merubah gaya belajar mereka juga. Mereka saat ini cenderung menyukai gaya belajar berbasis internet dan google. Mereka lebih interest di depan komputer mengakses materi dari internet dan google, daripada sekedar tatap muka dikelas. Mereka lebih senang berkumpul di café atau tempat belajar yang santai sambil berdiskusi. Inilah gaya belajar era milenial menggeser gaya belajar tradisional. Hal ini tentunya memiliki kelebihan namaun juga bisa berefek negatif terhadap eksistensi guru sebagai ruh dalam pembelajaran. Peluang dan tantangan selalu ada di setiap perubahan model pembelajaran di setiap era atau zaman.

Mengingat fenomena ini, maka guru bahasa Arab dituntut oleh keadaan untuk mengupgrade kemampuan mereka dalam mengikuti perkembangan tegnologi dan media pembelajaran. Guru bahasa Arab saat ini sudah dibekali berbagai skill baik yang berhubungan dengan keilmuan bahasa Arab, kependidikan maupun perkembangan tegnologi. Pelatihan-pelatihan diselenggarakan oleh pemerintah maupun otoritas sekolah baik negeri maupun swasta. Meskipun pada faktanya belum menyebar ke seluruh pelosok negeri indonesia. Tentunya ini menjadi catatan penting bagi pemangku kebijakan pemerintahan dalam hal ini adalah kementrian pendidikan.

Model pembelajaran siswa saat ini yang berbasis media sosial dan jejaring sosial lebih menyenangkan daripada bertatap muka. Saat ini sudah banyak belajar dengan mudah melalui komunitas di media sosial. Banyak lembaga non formal yang menyelenggarakan pembelajaran bahasa Arab secara online maupun daring melalui aplikasi facebook, instagram, whatsupp, aplikasi zoom, google meeting dan aplikasi daring lainnya. Sangat mudah dan praktis dalam belajar bahasa Arab. Materi-materi juga didesain semenarik mungkin agar memudahkan dan menjadikan siswa senang dalam belajar. Ditambah lagi perkembangan media multimedia dan android menjadikan materi didesain dalam bentuk tutorial sehingga bisa diakses dan dipelajari kapan saja dengan mudah melalui media kompoter dan internet.

Jika ini diterapkan akan membuat siswa suka dalam belajar bahasa Arab. Adapun langkah-langkah yang perlu dilakukan guru untuk membangkitkan potensi diri siswa dan minat siswa dalam belajar bahasa Arab adalah sebagai berikut: 
1. Mendeteksi tipe kecerdasan siswa dan cara belajarnya

2. Mendekati siswa secara personal dan sosial untuk mengetahui problem belajarnya dan problem yang mempengaruhi belajarnya.

3. Memberikan motivasi, memberikan tauladan dalam mengajar, dan memberikan reinforcement

4. Menerapkan pembelajaran dengan pendekatan "impian dan harapan"

5. Menerapkan pembelajaran dengan pendekatan "problem solving" dan "sharing pengalaman"

6. Menerapkan dasar-dasar "quantum teaching" di dalam kelas

7. Memberikan gambaran dan cerita dengan pendekatan "kisah-kisah inspiratif dalam pembelajaran bahasa Arab"

8. Menjelaskan akan pentingnya bahasa Arab tidak cukup sebagai mata pelajaran namun pentingnya dalam keberlangsungan kehidupan

9. Membangun "image" bahwa bahasa Arab adalah pelajaran yang sangat mudah dengan bukti bukti nyata

10. Ajarkan "berbahasa Arab" bukan "bahasa Arab"

11. Menjadi guru yang handal dan profesioal (berbahasa arab yang baik dan menggunakan media yang menarik dalam pembelajaran sesuai kebutuhan siswa).

\section{Kesimpulan}

Nilai-nilai Hipnoteaching diadopsi dalam pembelajaran bahasa Arab dengan konsep sebagai berikut, yaitu pada 1) Setting Tempat, Lokasi, Ruang Belajar bahasa Arab, 2) Setting mental dan psikologi diri guru dan siswa bahasa Arab, 3) Stimulus Awal Pembelajaran, 4) Setting gaya berkomunikasi dalam pembelajaran bahasa Arab, 5) Menghidupkan kelas dengan praktek tidak sekedar transfer ilmu atau pengetahuan bahasa Arab, 6) Evaluasi Pembelajaran Bahasa Arab, 7) Kegiatan Penutup Pembelajaran Bahasa Arab.

\section{Daftar Pustaka}

Agustian A G, Rahasia Sukses Membangkitkan ESQ POWER Sebuah Inner Journey melalui Ihsan, Jakarta: Arga, 2003.

Alrasi F, Pendekatan Metode Ekletik Terhadap Pembelajaran Bahasa Arab di AKPER Aisyiyah Padang, Jurnal Kajian dan Pengembangan Umat, Vol. 1, No. 1, 2018.

Abdul Wahab M, Pembelajaran Bahasa Arab di Era Post Metode, Arabiyat: Jurnal Pendidikan Bahasa Arab dan Kebahasaaraban, Vol. 2, No. 1, 2015.

Andrian Permata B, Teori GeneratifTransformatif Noam Chomsky dan Relevansinya Dalam Pembelajaran Bahasa Arab, Jurnal: Empirisma, Vol. 24, No. 2, Juli 2015.

Arifin Wijaya J, The secret Of Hypnosis: Mengungkap Rahasia hipnosis, mencegah, menghindari, dan menghadapi kejahatan Hipnosis, (Jakarta: Penebar Plus ${ }^{+}$2009).

Bimo, Pengantar Psikologi Umum, Yogyakarta: Andi Offside, 2016.

El-Fikry Ibrahim, Personal Power (Membuktikan 7 Rahasia Kekuatan Pribadi), Terj. Aisyah, (Kanada: Sales Master Press, 2002).

Gunawan W Ade, Hypnosis: The Art of Subconscious Communication, Meraih Sukses dengan Kekuatan Pikiran, (Jakarta: Pt. Gramedia Utama, 2007)

Hude D, Emosi: Penjelajahan ReligioPsikologis Tentang Emosi Manusia Di Dalam Al-Quran, Jakarta: Erlangga, 2006.

Hajar I, Hypno Teaching: Memaksimalkan Hasil Proses Belajar-Mengajar dengan Hipnoterapi, (Yogyakarta: Diva Press, 2011).

Hakim A, "Hypnosis in The Teaching: Cara Dahsyat Mendidik dan Mengajar”, (Jakarta: Visimedia, 2011).

Qodir A, "Humanistik" Teori Belajar Humanistik Dalam Meningkatkan Prestasi Belajar Siswa, Vol. 04, No.02, 2017.

Saripudin, Pengembangan Model Pembelajaran Abad 21 Dengan 
Menggunakan Tegnologi Web 2.0, Jurnal Teknodik, Vo. 19, No. 1, April 2015.

Suparlan, Teori Kontruktivisme Dalam Pembelajaran, Jurnal Islamika: Keislaman dan Ilmu Pendidikan, Vol. 1, No. 2, Juli 2019.

Suryabrata S, Psikologi Pendidikan, Grafindo Perkasa: Jakarta, 2002.

Syaodih Sukmadinata N, Landasan Psikologis Proses Pendidikan, (Bandung: PT Remaja Rosdakarya, 2003).

Webe A, "Smart Teaching 5 Metode Efektif Lejitkan Prestasi Anak didik", (Yogyakarta: Jogja Bangkit Publisher, 2010).

Winkel W.S, Peikologi Pendidikan dan Evaluasi Belajar, Gramedia, Jakarta, 1983.

Witherington, Psikologi Pendidikan, Jakarta:Aksara Baru, 1985.

Wong W\& Hakim A, "Dahsyatnya Hipnosis”, (Jakarta: Visimedia, 2010). 